\title{
NIBRAGEC

\section{ANÁLISE DO PROCESSO DE DEFINIÇÃO DE REQUISITOS DE DESEMPENHO EM EMPREENDIMENTOS BUILD TO SUIT ${ }^{1}$}

\author{
NUNES JUNIOR, Francisco Sales (1); ANDERY, Paulo Roberto Pereira (2) \\ (1) Universidade Federal de Minas Gerais, nunesfrancisco@gmail.com (2) Universidade Federal de \\ Minas Gerais, paulo@demc.ufmg.br
}

\begin{abstract}
RESUMO
"Build to suit", ou BTS, é um termo que identifica contratos de locação nos quais o imóvel é construído para atender os requisitos específicos do locatário já pré-determinado. Apesar da sua crescente aplicação no setor imobiliário, ainda são poucos os estudos apresentados na literatura brasileira acerca do tema. Este trabalho pretende contribuir com a gestão do processo de projeto em BTS, com foco na gestão de requisitos; o objetivo é caracterizar a definição de requisitos, desde a concepção do empreendimento, $e$ propor diretrizes para definição de requisitos relacionados às necessidades do usuário e atributos de performance da edificação. O estudo de casos conduzido incluiu a revisão do referencial teórico, entrevistas e avaliação de documentação de empresas inseridas em empreendimentos BTS implementados em Belo Horizonte (MG) e em São Paulo (SP). Os resultados da pesquisa apontaram para a adequada definição de requisitos pelo locatário (cliente final / usuário), porém, limitados a aspectos construtivos da edificação, cumprimento de normas e legislação, abordagem essa tradicional da construção. Observouse, portanto, significativa oportunidade para a proposição de diretrizes para melhoria da gestão de requisitos associados à performance do edifício em uso, objeto da abordagem "performance based design" $(P B D)$, o que se apresenta neste trabalho.
\end{abstract}

Palavras-chave: "Build to suit”, Requisitos de projeto, Requisitos do usuário, "Performance based design".

\begin{abstract}
Build to suit, or BTS, is a term that identifies the lease contracts in which the property is built to meet the specific requirements of the client (tenant). Despite its growing application in the real estate sector, there are still few important studies in the Brazilian literature on the subject. This work intends to contribute to the management of the project process in BTS, focusing on requirements management and its relationship with the needs of the user and with the performance attributes of the building. The case study here presented was conducted in the context of a developed research of BTS projects implemented in Belo Horizonte (MG) and São Paulo (SP). The study included a revision of the theoretical framework, interviews, and documentation evaluation. The results point to the adequate definition of requirements by the client (lessee and user), which supported the conception of the projects and its execution by the lessor. These requirements refer to the construction aspects of building, compliance with standards and legislation, as defined by the traditional approach to construction. Therefore, there are opportunities for proposing guidelines for improving the management of requirements associated with building performance in use, object of the performance-based design approach (PBD), which is presented in this work.
\end{abstract}

Keywords: Build to suit, Project requirements, User requirements, Performance based design.

${ }^{1}$ NUNES JUNIOR, F.S.; ANDERY, P.R.P. Análise do processo de definição de requisitos de desempenho em empreendimentos build to suit. In: SIMPÓSIO BRASILEIRO DE GESTÃO E ECONOMIA DA CONSTRUÇÃO, 12., 2021, Maceió. Anais[...] Porto Alegre: ANTAC, 2021. p.1-8. Disponível em: https://eventos.antac.org.br/index.php/sibragec/article/view/496. Acesso em: 2 out. 2021. 


\section{INTRODUÇÃOO}

Build to suit, built to suit, ou simplesmente BTS, como é usualmente identificado, é uma expressão em língua inglesa, utilizada pelo setor imobiliário para identificar contratos de locação a longo prazo no qual o imóvel é construído para atender os interesses do locatário, já pré-determinado. Segundo Caríelo (2014), trata-se de uma modalidade contratual amplamente difundida nos Estados Unidos a partir da década de 1950, porém recente no Brasil, onde é datada da década de 1990 e somente regulamentada pela Lei 12744/12, de 19 de dezembro de 2012.

Esse tipo de contrato é chamado de "contrato de construção ajustada" e definido pela lei brasileira como sendo uma modalidade de locação não residencial de imóvel urbano, na qual o locador procede à prévia aquisição, construção ou substancial reforma, por si mesmo ou por terceiros, de imóvel previamente especificado pelo pretendente à locação (locatário). O imóvel então construído é locado por prazo determinado em comum acordo entre as partes (locador e locatário). Segundo Ferriane (2013), o contrato BTS confere benefícios de diversas naturezas para o locatário. O principal destes benefícios deriva do fato de que o locatário (usuário) não realiza imobilização de capital destinado ao exercício de sua atividade fim na construção do imóvel. A opção pela locação pode possibilitar ainda ganhos financeiros e tributários, a depender do regime de tributação adotado pela pessoa jurídica do locatário.

Quando comparado a outros temas do mercado imobiliário, são poucos os autores e trabalhos acerca do BTS, o que torna o tema mais difícil, porém ainda mais atraente e repleto de oportunidades para aprofundamento através da pesquisa científica. Ainda mais considerando-se o crescimento desta modalidade no mercado imobiliário brasileiro.

O objetivo do estudo foi, através da pesquisa realizada, caracterizar o processo de definição de requisitos do usuário em empreendimentos BTS, e propor diretrizes para a definição de requisitos relacionados ao desempenho da edificação em uso, ou seja, na etapa de operação e manutenção do ambiente construído. Enquanto é amplamente estudado o processo de projeto e definição de requisitos para as etapas de planejamento, projeto e construção, é significativamente menor o número de estudos voltados especificamente à garantia do desempenho nas etapas pós-construção. Assim, o estudo conduzido visa contribuir para o processo de definição de requisitos do usuário com foco na garantia de atendimento aos atributos de desempenho na etapa de uso, operação e manutenção do ambiente construído, requisitos esses definidos na fase de concepção do empreendimento.

\section{MÉTODO}

O estudo foi desenvolvido no marco metodológico de estudo de caso. A pesquisa envolveu: (i) revisão bibliográfica, considerando a conceituação do BTS, requisitos e atributos de desempenho da edificação em uso e projeto para o desempenho, ou performance based design; (ii) definição de protocolo dos estudos de casos; (iii) condução de estudos de casos exploratórios; (iv) a partir da análise dos casos, caracterização do processo de definição de requisitos em BTS; (v) proposição preliminar de diretrizes para o processo de definição de requisitos do usuário em BTS com foco no desempenho da edificação em uso, em linha com o referencial teórico analisado. O procedimento metodológico seguiu o fluxograma apresentado na Figura 1.

Os estudos de casos foram conduzidos junto a empresas instaladas nas regiões metropolitanas de Belo Horizonte (MG) e São Paulo (SP), que participaram como agentes centrais na implantação de empreendimentos BTS nessas regiões. As fontes de evidências utilizadas foram as informações coletadas nas entrevistas com os principais executivos das empresas e documentos técnicos fornecidos. 
Figura 1 - Fluxograma do procedimento metodológico

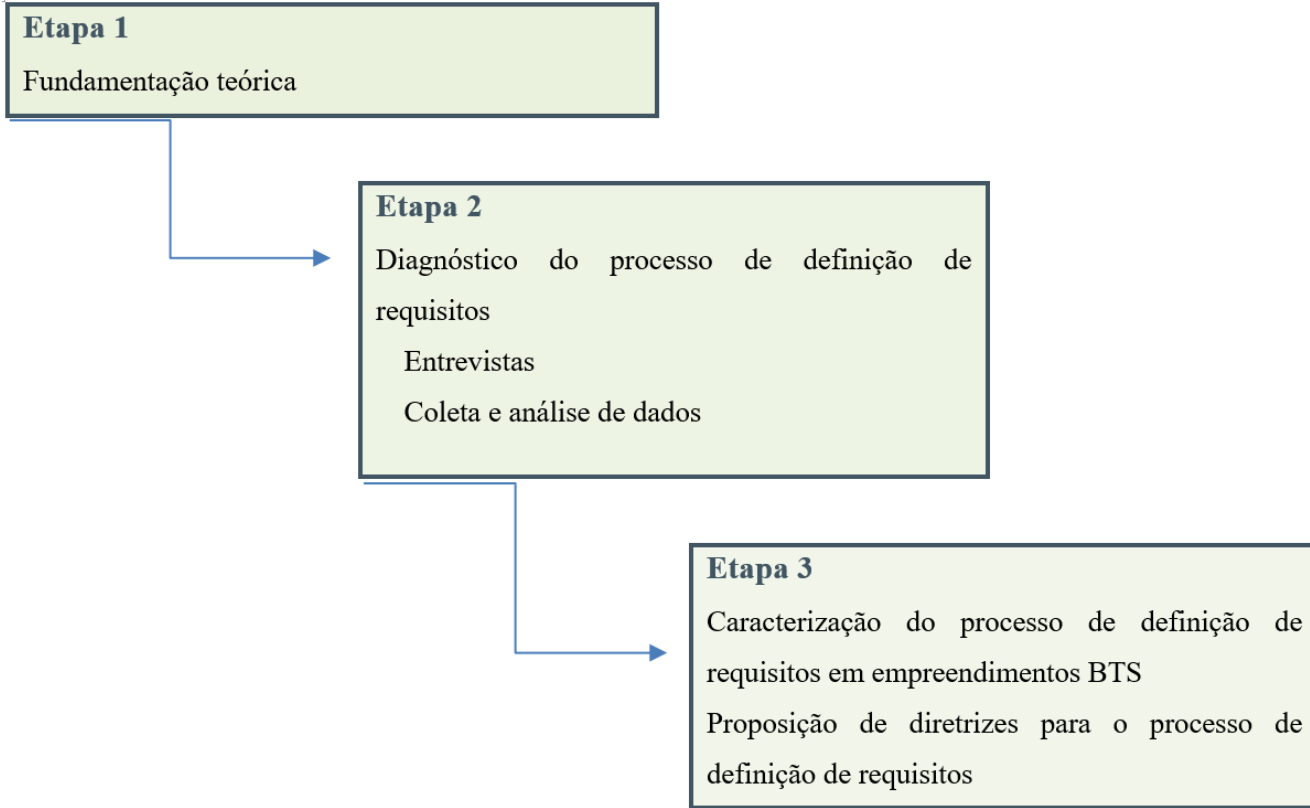

Fonte: Autores

Apresentam-se na Figura 2 as empresas e empreendimentos estudados.

Figura 2 - Empresas e empreendimentos estudados
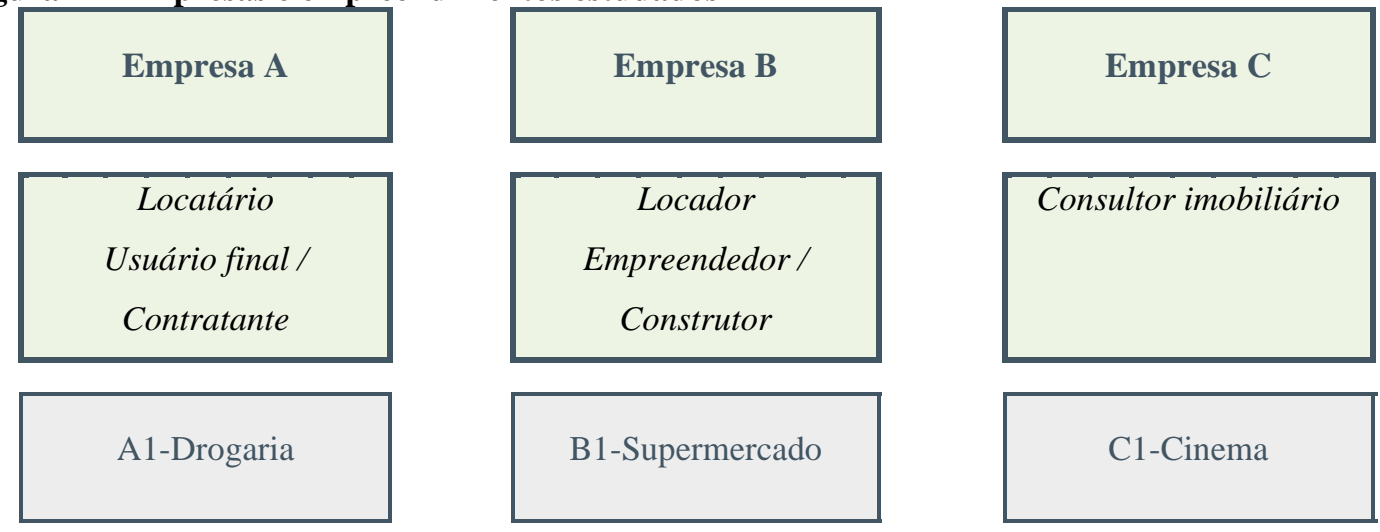

B1-Supermercado

C1-Cinema

B2-Supermercado

C2-Cinema

B3-Galpão logístico

C3-Academia

Belo Horizonte (MG)

São Paulo (SP)

Fonte: Autores

A Empresa A é uma rede varejista de drogarias, atuante na região metropolitana de Belo Horizonte (MG) há mais de cinquenta anos. O empreendimento estudado é uma drogaria padrão da empresa, edificação, portanto, similar às demais drogarias instaladas e em funcionamento na região metropolitana de Belo Horizonte (MG). A Empresa A é o agente locatário, usuário final e contratante nos seus empreendimentos BTS.

A Empresa B é uma empresa atuante na região metropolitana de Belo Horizonte (MG) e especializada na estruturação e implantação de empreendimentos BTS. É o agente 
locador, também responsável pela construção do imóvel, sendo, portanto, empreendedor, construtor e locador nos seus empreendimentos BTS. Os empreendimentos estudados foram dois supermercados, pertencentes a duas diferentes redes varejistas, e um galpão logístico para recebimento, armazenamento e distribuição de produtos de terceiras empresas comerciais, todos esses implantados na região metropolitana de Belo Horizonte (MG).

A Empresa C é uma empresa de consultoria imobiliária, atuante na região metropolitana de São Paulo (SP). Dentre os vários serviços do seu portfólio empresarial, presta consultoria para locadores e locatários na estruturação e implantação de empreendimentos BTS. Os empreendimentos estudados foram dois cinemas, pertencentes a diferentes redes de cinemas que operam em várias cidades do país, e uma academia, todos esses implantados na região metropolitana de São Paulo (SP).

Informações coletadas nas entrevistas com os principais executivos das três empresas constituíram as principais fontes de evidências, além de documentos técnicos fornecidos pela Empresa C. As Empresas A e B não forneceram documentos escritos, por questões de confidencialidade. O empreendimento A1-Drograria foi definido como estudo de caso piloto e, com base neste, fez-se a validação do protocolo de estudo e então sua aplicação nos outros estudos de casos.

\section{A DEFINIÇÃO DE REQUISITOS NO BTS}

Segundo Cilli (2004), em mercados maduros como na Europa e nos Estados Unidos, os requisitos do locatário / usuário - contratante do BTS - são definidos em documentos chamados requisição para qualificação e requisição de proposta. Esses termos em português são traduções dos termos em inglês utilizados nesses mercados, quais sejam, respectivamente, request for qualification (RFQ) e request for proposal (RFP).

A RFQ é entendida como edital de consulta prévia ao mercado para a seleção de número limitado de empresas (empreendedores, futuros locadores) que se mostrarem, a priori, qualificados para participarem do processo de contratação do empreendimento. Na RFQ, o contratante (locatário) apresenta as características técnicas gerais do empreendimento, as características contratuais e os critérios de seleção e requisitos da contratada (futuro locador).

As empresas qualificadas na RFQ então recebem a RFP, edital formal de concorrência, para a apresentação de sua proposta para a implantação do empreendimento. A RFP deve conter informações completas que caracterizam o empreendimento e o contrato. Deve conter ainda todos os requisitos do contratante a serem observados pela contratada, desde a seleção e aquisição do terreno, elaboração e aprovação de projetos, construção e entrega do imóvel. Em resposta à RFP, o empreendedor emite sua proposta para a implantação do empreendimento nos termos da RFP.

A RFP pode também conter requisitos associados a atributos de desempenho do ambiente construído. Esses requisitos foram estudados por Becker e Foliente (2005) no âmbito da abordagem denominada "projeto para o desempenho", ou performance based design (PBD). Os atributos de desempenho são categorizados nos quatro principais grupos a seguir descritos e relacionam-se à melhor eficiência e desempenho da edificação em uso:

- Funcionalidade: características espaciais e de acessibilidade, serviço, operação e manutenção;

- Segurança: estrutural, proteção contra incêndio, segurança contra acidentes, segurança para pessoas, segurança patrimonial;

- Saúde e bem-estar: qualidade do ar, climatização, acústica, conforto visual, higiene, qualidade da água;

- Sustentabilidade: eficiência energética, durabilidade, impacto ambiental. 


\section{RESULTADOS E PROPOSIÇÃO DE DIRETRIZES}

Nesta seção apresentam-se os resultados do estudo, quais sejam, a caracterização dos processos de implantação de empreendimentos BTS e de definição de requisitos, a avaliação do nível de aderência desses processos em relação ao referencial teórico estudado e sua correlação com o modelo de negócio. A partir das observações realizadas, sugerem-se diretrizes para o processo de definição de requisitos, com base na avaliação dos casos estudados e no referencial teórico.

\subsection{Resultados}

Nos empreendimentos estudados, os requisitos do locatário / usuário são registrados em documento técnico, denominado memorial descritivo (denominação geral aplicada no setor imobiliário, podendo haver variações no título, porém mantém-se o conteúdo técnico geral). Na medida do necessário, os requisitos são também anotados em desenhos e documentos de projetos de arquitetura, e são objeto de discussão entre contratante (locatário / usuário) e contratado (locador / empreendedor) e anotados em atas de reunião entre as partes. Todos esses documentos passam a ser anexos do contrato BTS assinado entre locador e locatário.

Os requisitos no memorial descritivo são relacionados aos aspectos construtivos da edificação, a ser entregue no shell pelo locador ao locatário. Por entrega no shell (concha, na tradução do inglês), entende-se a construção e entrega do imóvel com estrutura e fechamento (fechamento lateral e cobertura) concluídos, bem como sistemas e interligações do imóvel à rede pública externa de água, efluentes e energia. Estarão a cargo do locatário todas as atividades necessárias à completação do imóvel, incluindo-se, mas não se limitando a acabamentos externo e interno, paisagismo, compartimentação interna, sistemas internos de energia, iluminação, segurança, sistemas condicionamento de temperatura ambiente, entre outros.

O locador recebe os requisitos para aplicação nos projetos e construção, limitando-se ao shell, não cabendo a ele a revisão ou o desenvolvimento de novos requisitos. O papel do locador na implantação aproxima-se de uma construção por empreitada que, segundo Cardoso (2016), inclui todos os projetos e estudos necessários, execução, fornecimento, transporte, instalação e montagem de todos os equipamentos, mão-de-obra, materiais e os demais recursos necessários à efetiva conclusão da edificação e ao bom funcionamento de todos os sistemas, de acordo com os requisitos do contratante.

Não são incluídos no memorial, entretanto, requisitos associados à performance do edifício em uso, como definem Becker e Foliente (2005) no âmbito da abordagem performance based design (PBD).

Nos empreendimentos estudados, o processo de definição de requisitos em BTS é realizado em duas fases bastantes distintas:

1. Definição de requisitos pelo locatário no memorial descritivo, relativos à forma como a edificação deve ser construída até o shell;

2. Definição de requisitos pelo locatário para completação do imóvel, operação e manutenção. Esses requisitos, mais próximos do que define a abordagem PBD, são tomados pelo próprio locatário para a contratação dos projetos e obras complementares, necessários à efetiva conclusão da edificação.

O estudo de casos permitiu identificar oportunidades para a melhor definição de requisitos em BTS, à luz do referencial teórico:

- Definição de requisitos relacionados a melhores níveis e desempenho e eficiência da edificação em uso; 
- Participação do locador, em conjunto com o locatário, na definição dos requisitos relacionados à elaboração de projetos, construção, operação e manutenção, permitindo o intercâmbio técnico entre esses diferentes agentes;

- Participação antecipada de terceiras empresas de projeto e consultorias especializadas na definição de requisitos, com foco no desenvolvimento de soluções otimizadas quanto à implantação (custo, prazo, consuntibilidade), operação e manutenção.

Diante das oportunidades identificadas e com base no referencial teórico analisado, apresenta-se na seção seguinte uma proposta preliminar de diretrizes para a melhor definição de requisitos do usuário no BTS. Tal proposta pretende preencher as lacunas identificadas, bem como oferecer caminhos para a melhoria dos processos estudados.

\subsection{Proposição preliminar de diretrizes}

Apresenta-se no Quadro 1 uma proposição preliminar de diretrizes para a definição de requisitos do usuário com foco no desempenho da edificação.

\section{Quadro 1 - Proposição preliminar de diretrizes para a definição de requisitos do usuário}

\# $\quad$ Diretriz $\quad$ Considerações adicionais

\begin{tabular}{|c|c|c|}
\hline 1 & $\begin{array}{l}\text { Definir as funcionalidades principais da } \\
\text { edificação. }\end{array}$ & $\begin{array}{l}\text { Foco na gestão otimizada das áreas do ambiente } \\
\text { construído, acessibilidade, manutenção, durabilidade, } \\
\text { eficiência energética. }\end{array}$ \\
\hline 2 & Definir os atributos de desempenho. & $\begin{array}{l}\text { Atributos de desempenho da edificação em uso: } \\
\text { - Funcionalidade: acessibilidade, serviço, operação e } \\
\text { manutenção; } \\
\text { - Segurança: estrutural, proteção contra incêndio, } \\
\text { segurança contra acidentes, segurança para pessoas, } \\
\text { segurança patrimonial; } \\
\text { - Saúde e bem-estar: qualidade do ar, climatização, } \\
\text { acústica, conforto visual, higiene, qualidade da } \\
\text { água; } \\
\text { - Sustentabilidade: eficiência } \\
\text { durabilidade, impacto ambiental. }\end{array}$ \\
\hline 3 & Definir as metas de desempenho. & $\begin{array}{l}\text { As metas de desempenho devem levar em } \\
\text { consideração: } \\
\text { (1) Quanto aos usuários e operadores do ambiente } \\
\text { construído: } \\
\text { - Completa caracterização dos seus perfis; } \\
\text { - Suas necessidades; } \\
\text { - As atividades a serem desenvolvidas; } \\
\text { (2) Quanto ao empreendimento: } \\
\text { - Adição de valor ao projeto (funcionalidade, } \\
\text { otimização, durabilidade, ganho empresarial); } \\
\text { - Aplicação positiva e não conflitante com o todo o } \\
\text { ciclo de vida da edificação. }\end{array}$ \\
\hline
\end{tabular}




\begin{tabular}{|c|c|c|}
\hline$\#$ & Dirt & s adicionais \\
\hline 4 & $\begin{array}{l}\text { Avaliar restrições para o atingimento das } \\
\text { metas e propor soluções. }\end{array}$ & $\begin{array}{l}\text { Restrições internas (empresariais, locação, projeto, } \\
\text { contratações etc.) e externas (mercado, normas e } \\
\text { códigos, leis etc.). }\end{array}$ \\
\hline 5 & $\begin{array}{l}\text { Testar soluções propostas (projeto e } \\
\text { simulações) e identificar a solução mais } \\
\text { satisfatória e eficaz. }\end{array}$ & $\begin{array}{l}\text { Estudos comparativos de arquitetura e engenharia, } \\
\text { simulações computacionais. }\end{array}$ \\
\hline 6 & $\begin{array}{l}\text { Estabelecer ordem de prioridade para } \\
\text { metas. }\end{array}$ & $\begin{array}{l}\text { Considerar viabilidade técnica de implantação, custo } \\
\text { associado e valor agregado ao negócio. }\end{array}$ \\
\hline 7 & $\begin{array}{l}\text { Definir os indicadores de desempenho, } \\
\text { incluindo: } \\
\text { - Descrição do indicador; } \\
\text { - Nível de satisfação, insatisfação ou } \\
\text { falha; } \\
\text { - Valores limites para cada nível de } \\
\text { satisfação. }\end{array}$ & $\begin{array}{l}\text { Indicadores mensuráveis e em linha com as metas, } \\
\text { atributos e funcionalidades. }\end{array}$ \\
\hline 8 & $\begin{array}{l}\text { Validar a correlação positiva entre o } \\
\text { diferentes indicadores e metas. }\end{array}$ & $\begin{array}{l}\text { Estudos comparativos de arquitetura e engenharia, } \\
\text { simulações computacionais. }\end{array}$ \\
\hline 9 & $\begin{array}{l}\text { Determinar os fatores de segurança para } \\
\text { transformar os valores dos indicadores } \\
\text { em valores de projeto. }\end{array}$ & $\begin{array}{l}\text { Entradas quantitativas a serem tomadas como } \\
\text { referência na etapa seguinte de elaboração de projetos } \\
\text { de arquitetura e engenharia. }\end{array}$ \\
\hline 10 & $\begin{array}{l}\text { Definir os requisitos e critérios de } \\
\text { projetos de arquitetura e engenharia. }\end{array}$ & $\begin{array}{l}\text { Dados básicos e critérios para a elaboração de projetos } \\
\text { de arquitetura e engenharia }\end{array}$ \\
\hline 11 & $\begin{array}{l}\text { Validar a correlação positiva entre os } \\
\text { requisitos de desempenho e os } \\
\text { requisitos/critérios de projetos. }\end{array}$ & projeto. \\
\hline 12 & $\begin{array}{l}\text { Aferir a eficácia do ambiente construído } \\
\text { quanto ao atingimento das metas de } \\
\text { desempenho e objetivos do negócio. }\end{array}$ & $\begin{array}{l}\text { Medições em campo, testes e simulações e avaliação } \\
\text { comparativa com os requisitos e soluções de projeto. }\end{array}$ \\
\hline 13 & $\begin{array}{l}\text { Retroalimentar o processo de definição de } \\
\text { requisitos. }\end{array}$ & $\begin{array}{l}\text { Revisar definições anteriores para seu ajuste e melhor } \\
\text { aplicação nos projetos futuros. }\end{array}$ \\
\hline
\end{tabular}

Fonte: Autores

\section{CONSIDERAÇÕES FINAIS}

O trabalho desenvolvido por meio de estudo de caso exploratório permitiu caracterizar o caracterizados o processo de implantação de empreendimentos BTS, o processo de definição de requisitos e o nível de aderência desses processos em relação ao referencial teórico estudado. Observou-se a definição de requisitos pelo locatário (usuário), os quais se aplicam à definição de materiais e aspectos construtivos da edificação, em geral limitados ao cumprimento do que dispõem códigos prescritivos, normas técnicas e legislação (abordagem tradicional de construção). Ficaram evidenciadas oportunidades para a definição de requisitos associados ao desempenho do edifício em uso, as quais suscitaram a proposição preliminar de diretrizes apresentada neste artigo. 
Ressalta-se a importância do desempenho da edificação, em sua etapa de operação, para o resultado empresarial do empreendimento. Neste sentido, parece ser evidente que o desenvolvimento de soluções que aumentem a performance da edificação em aspectos relacionados ao gerenciamento e uso do espaço, eficiência energética, consumo de água, entre outras, impactarão diretamente o resultado do empreendimento. Outros estudos futuros podem ser realizados a partir dos dados coletados e resultados alcançados, para maior aprofundamento na modalidade BTS e o melhor desempenho das edificações, relações de interface entre os agentes em cada empreendimento e o resultado do negócio.

\section{REFERENCIAS}

BECKER, R.; FOLIENTE, G. Performance Based International State of the Art. PeBBu 2nd International SotA Report. In: CIBdf - International Council for Research and Innovation in Building and Construction-Development Foundation. Rotterdam, 2005.

BRASIL. Lei 12.744, de 19 de dezembro de 2012. Altera o art. $4^{\circ}$ e acrescenta art. 54A à Lei no 8.245, de 18 de outubro de 1991, que "dispõe sobre as locações dos imóveis urbanos e os procedimentos a elas pertinentes", para dispor sobre a locação nos contratos de construção ajustada. Brasília, 19 de dezembro de 2012. Disponível em: https://www.planalto.gov.br/ccivil_03/_ato2011-2014/2012/lei/112744.htm. Acesso em: 07 de março de 2020.

CARDOSO, R. A. de A. Gestão de contratos EPC em regime turnkey, com base em contratos tipo FIDIC. 2016. Dissertação. Mestrado Integrado em Engenharia Civil Departamento de Engenharia Civil, Faculdade de Engenharia da Universidade do Porto, Porto, Portugal, 2016.

CARÍELO, D. P. Contrato built to suit e as inovações acarretadas pela lei $\mathbf{n}^{\mathbf{0}}$ 12.744/12. 2014. Disponível em: http://ambitojuridico.com.br/site/?n_link= revista _artigos_leitura\&artigo_id=15251. Acesso em: 18 de janeiro de 2019.

CILLI, F. Empreendimentos do tipo build-to-suit: arbitragem do valor de locação em editais de concorrência. 2004. Monografia (MBA em Gerenciamento de Empresas e Empreendimentos na Construção Civil com Ênfase em Real Estate) - Programa de Educação Continuada em Engenharia, USP, São Paulo, 2004.

FERRIANI, A. O contrato build to suit e a lei 12744/12. 2013. Disponível em: https://www.migalhas.com.br/coluna/civilizalhas/170851/o-contrato-built-to-suit-e-alei-12744-12. Acesso em: 20 de janeiro de 2019. 